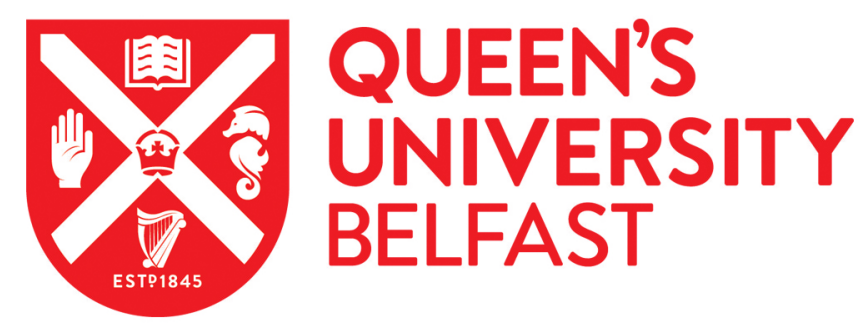

\title{
Experimental Saltwater Intrusion in Coastal aquifers Using Automated Image Analysis: Applications to Homogeneous Aquifers.
}

Robinson, G., Ahmed, A. A., \& Hamill, G. A. (2016). Experimental Saltwater Intrusion in Coastal aquifers Using Automated Image Analysis: Applications to Homogeneous Aquifers. Journal of Hydrology, 538, 304-313. https://doi.org/10.1016/j.jhydrol.2016.04.017

Published in:

Journal of Hydrology

Document Version:

Peer reviewed version

Queen's University Belfast - Research Portal:

Link to publication record in Queen's University Belfast Research Portal

Publisher rights

(C) 2016 Elsevier. This manuscript version is made available under the CC-BY-NC-ND 4.0 licensehttp://creativecommons.org/licenses/by-ncnd/4.0/, which permits distribution and reproduction for non-commercial purposes, provided the author and source are cited.

\section{General rights}

Copyright for the publications made accessible via the Queen's University Belfast Research Portal is retained by the author(s) and / or other copyright owners and it is a condition of accessing these publications that users recognise and abide by the legal requirements associated with these rights.

Take down policy

The Research Portal is Queen's institutional repository that provides access to Queen's research output. Every effort has been made to ensure that content in the Research Portal does not infringe any person's rights, or applicable UK laws. If you discover content in the Research Portal that you believe breaches copyright or violates any law, please contact openaccess@qub.ac.uk. 


\title{
Experimental Saltwater Intrusion in Coastal aquifers Using Automated Image Analysis:
}

\section{Applications to Homogeneous Aquifers}

\author{
G. Robinson, Ashraf A Ahmed ${ }^{1}$ and G.A. Hamill
}

School of Planning, Architecture, and Civil Engineering, Queen's University Belfast, David Keir building, Stranmillis Road, Belfast BT95AG, UK.

\begin{abstract}
This paper presents the applications of a novel methodology to quantify saltwater intrusion parameters in laboratory-scale experiments. The methodology uses an automated image analysis procedure, minimizing manual inputs and the subsequent systematic errors that can be introduced. This allowed the quantification of the width of the mixing zone which is difficult to measure in experimental methods that are based on visual observations. Glass beads of different grain sizes were tested for both steady-state and transient conditions. The transient results showed good correlation between experimental and numerical intrusion rates. The experimental intrusion rates revealed that the saltwater wedge reached a steady state condition sooner while receding than advancing. The hydrodynamics of the experimental mixing zone exhibited similar traits; a greater increase in the width of the mixing zone was observed in the receding saltwater wedge, which indicates faster fluid velocities and higher dispersion. The angle of intrusion analysis revealed the formation of a volume of diluted saltwater at the toe position when the saltwater wedge is prompted to recede. In addition, results of different physical repeats of the experiment produced an average coefficient of variation less than 0.18 of the measured toe length and width of the mixing zone.
\end{abstract}

\section{Keywords}

Saline water intrusion; Intrusion angle; Width of the mixing zone; Light to concentration conversion.

\footnotetext{
${ }^{1}$ Corresponding author Email: a.ahmed@qub.ac.uk Tel: +44(0)2890974015 Fax: +44(0)2890974278
} 


\section{Introduction}

The sustainable management of groundwater resources in coastal aquifers is important to protect them from saltwater intrusion (SWI) that occurs naturally within these aquifers. SWI occurs because of the density difference between the denser saltwater in the sea and the lighter freshwater in the aquifer. Other factors such as the rise of sea water levels due to climate change, and over-pumping from the aquifer may promote further intrusions. It is therefore important to find ways to reduce further SWI in coastal aquifers.

Many studies have investigated the problem of SWI (e.g. Zhang et al., 2002; Goswami and Clement, 2007; Werner et al., 2013; Chang and Clement, 2012, 2013). Goswami and Clement (2007) presented laboratory scale results from sandbox experiments with the goal of providing new benchmark data sets for validating numerical SWI codes. They also identified a zone of brackish water between the freshwater and saltwater, but due to the small scale they like many other studies, assumed a sharp interface between saltwater and freshwater and negated analysing the width of the mixing zone (WMZ). However, the above studies have characterised SWI parameters using visual observation, which is labour intensive, limits the spatial and temporal resolutions of the data, and is prone to human error.

The dynamics of the mixing zone have not been extensively analysed in laboratory experiments due to the high precision measurements required to map density variations over small length scales. However, the mixing zone plays an important role in SWI and affects the discharge of freshwater in the coastal environment, saltwater circulation and reactive transport processes (Zhang et al., 2002; Werner et al., 2013). Laboratory scale mixing zones are small, but field scale studies have reported mixing zones kilometres in size, making quantification of WMZ essential for effective water resource management (Werner et al., 2013). The mixing zone is also important for biological and chemical processes, and is a transport pathway for exchange of nutrients, metals and organic compounds (Spiteri et al., 2008). Therefore, the hydrodynamics of the mixing zone is an integral part of SWI and the lack of quantified experimental data provides great scope for investigation.

Nevertheless, several experimental studies have investigated SWI for an array of different problems in synthetic homogeneous aquifers without quantifying the WMZ (Goswami and 
Clement, 2007; Werner et al., 2009; Luyun et al., 2011; Shi et al., 2011; Jakovovic et al., 2012; Stoeckl and Houben, 2012; Morgan et al., 2013; Lu et al., 2013; Chang and Clement, 2012, 2013; Dose et al., 2014). Werner et al. (2009) investigated laboratory scale saltwater upconing at extraction wells and compared the results to an analytical sharp interface solution. Their results indicated strong dispersive processes dominating the initial phases due to a gradual increase in salinity measured in the extracted water. However, due to measuring the saltwater up-coning by visual observation they were unable to determine density variations within the up-coning plume. Chang and Clement (2012) investigated the impacts of freshwater flux boundaries on SWI in homogeneous laboratory scale aquifers. Chang and Clement (2013) further studied SWI transport processes by tracing dyed plumes, injected both inside the saltwater wedge and in the freshwater zone. Both studies involved in-depth analysis of finite element numerical simulations, where high resolution spatial data is readily available, and from these results postulated theories about intrusion dynamics. In most cases, the experimental results qualitatively confirmed the numerical hypotheses, but the lack of high resolution image to concentration conversion did not allow for quantification of density variations within the experimental saltwater wedge. One of the few experimental studies to focus on determining the mixing zone properties was presented by Abarca and Clement (2009). They developed a method of mapping the mixing zone by utilising the colourimetric changes of phenolphthalein under the different $\mathrm{pH}$. However, despite identifying the clear presence of a mixing zone, no quantitative experimental results were presented. The size and position of the mixing zone were compared to numerical simulations by visual observation only.

From our review of the literature, there does not appear to be a singular study that compares and investigates the effect of particle grain size on laboratory scale SWI. Numerical sensitivity analyses by Abarca (2006) and Dentz et al. (2006) revealed that SWI parameters (eg. toe length $(T L), W M Z$ ) depend significantly on aquifer permeability and dispersivity values, which are both related to the size of the porous media grains. Therefore, in order to understand the effects of heterogeneity on SWI, it is important to quantify the hydrodynamic differences between homogeneous aquifers of differing grain diameters. Another aspect of experimental SWI that is rarely discussed in the literature is the repeatability. This may be attributed to the long time needed to conduct such experiments. The only mention of repeatability was found 
in Karasaki et al. (2006), who presented results of a repeat experimental test case conducted 6 months after the original. They found large differences between the results, but attributed the discrepancies to the degradation of the metal permeable meshes at the tank boundaries. Nevertheless, the results pose the question of the repeatability in SWI laboratory experiments, which as yet remains unanswered.

Most of the limitations mentioned above have been addressed in this study. Therefore, the current experimental study achieves high spatial and temporal resolutions permitting the analysis of mixing zone dynamics under the effects of transient conditions. Furthermore, this study examines the hypotheses developed by numerical investigations and compares them with experimental results. The effect of grain diameter is also investigated and compared with numerical simulations. Finally, the repeatability of the experiment is determined through a combination of physical reconstruction repeats and test case repeats.

\section{Experimental setup and test cases}

The sandbox and instrumentation used in the experiment are described in Robinson et al. (2015). The tank consisted of a central viewing chamber of dimensions (Length $x$ Height $x$ Depth) $0.38 \mathrm{~m} \times 0.15 \mathrm{~m} \times 0.01 \mathrm{~m}$ made from clear Perspex, and flanked by two large chambers at either side to provide the hydrostatic pressure boundary conditions. The left and right chambers were filled with fixed head freshwater and dyed saltwater respectively. A light diffuser was fitted to the back of the rig and two LED lights were used to provide the illumination. Saltwater concentration was correlated with the intensity of the light transmitting through the main chamber, which is filled with glass beads. Intrusion images were captured with an IDT ${ }^{\circledR}$ MotionPro X-Series high speed camera with a capture resolution of $1280 \times 1024$ pixels and an 8-bit grayscale pixel depth. The resolution allowed for a pixel size of around $0.3 \mathrm{~mm}$ and the grayscale pixel depth provided a range of 256 available light intensities without the need for RGB to grayscale conversion or channel isolation. Ten images were taken each time the camera was triggered (every 30 seconds) and the average of these images was used in the analysis. The light intensity-concentration conversion is determined through a calibration procedure, which is discussed in detail in Robinson et al. (2015).

The test cases involved packing glass beads of a single diameter class in a uniform distribution, so that the media could be considered homogenous and isotropic. Glass beads were siphoned 
into the sandbox in order to prevent air entrapment and maintain fully saturated conditions. The beads were packed in three separate layers and tamped evenly to provide uniform compaction and satisfy the homogeneous conditions required. Three different bead diameter classes were investigated, $780 \mu \mathrm{m}, 1090 \mu \mathrm{m}$ and $1325 \mu \mathrm{m}$, as shown in Fig 1.
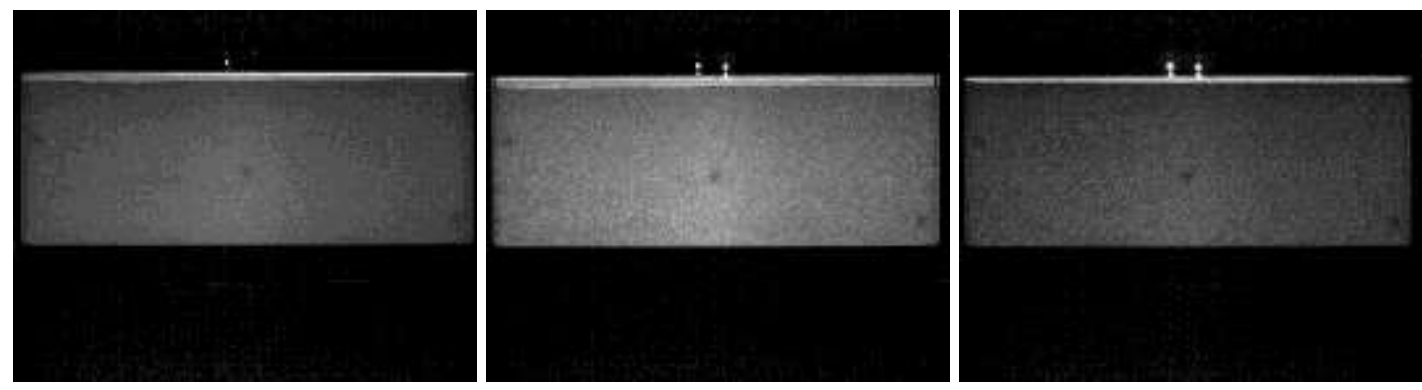

Fig 1 - Raw camera images of the 3 homogeneous bead classes: $780 \mu \mathrm{m}$ (left), $1090 \mu \mathrm{m}$ (middle) and $1325 \mu \mathrm{m}$ (right)

Initially, the aquifer was totally flushed with freshwater and contained no saltwater. A head difference $(\mathrm{dH})$ of $6 \mathrm{~mm}$ was imposed across the aquifer by adjusting the overflow outlets in the saltwater and freshwater side chambers, prompting the dyed saltwater to intrude into the central viewing chamber. Images of the saltwater wedge were recorded every 5 minutes until a steady state condition was reached (50 minutes). The head difference was then decreased to $d H=4 \mathrm{~mm}$, reducing the hydraulic gradient and prompting the saltwater wedge to move further inland. The transient advancing movements of the saltwater wedge were captured by the camera similarly to the $d H=6 \mathrm{~mm}$ case. After a steady state condition was achieved, the receding saltwater wedge dynamics were analysed by increasing the head difference to $d H=5 \mathrm{~mm}$. This resulted in 3 head differences producing 3 different steady state conditions of the saltwater wedge, therefore allowing the experimental results to be used to test steady state only numerical codes as well as transient numerical codes. Finally, the head difference was increased back up to $d H=6 \mathrm{~mm}$, returning to the initial head difference condition in order to investigate any hysteresis effects. Table 1 summarises the homogeneous test cases conducted.

For each bead diameter, the experiment was conducted 3 times. These repeats were termed 'physical repeats', which included the removal and replacement of the same bead class and repetition of all the head difference tests. This allowed the repeatability of the experiment to 
be analysed and permitted the assessment of non-homogeneous effects introduced in the bead packing stage. An additional repeat for the $1090 \mu \mathrm{m}$ diameter bead class was run as a control in order to quantify the differences between packing the beads using controlled tamping versus letting the beads fall in place under gravitational effects (no tamping).

Table 1 - Experimental homogeneous test case summary

\begin{tabular}{|c|c|c|c|c|}
\hline $\begin{array}{c}\text { Bead } \\
\text { Diameter }(\mu \mathrm{m})\end{array}$ & $\begin{array}{l}\text { Physical } \\
\text { Repeats }\end{array}$ & Steady State $d H$ & Transient $d H$ & $\begin{array}{l}\text { Temporal } \\
\text { Resolution(/min) }\end{array}$ \\
\cline { 1 - 2 } 780 & 3 & $6 \mathrm{~mm}$ & f-6mm, 6-4mm, & 0.2 \\
\cline { 1 - 2 } 1090 & 4 & $4 \mathrm{~mm}$ & $4-5 \mathrm{~mm}, 5-6 \mathrm{~mm}$ & 0.2 \\
\cline { 1 - 2 } & 3 & $5 \mathrm{~mm}$ & & 0.2 \\
\hline
\end{tabular}

\section{Numerical modelling approach}

The results from the experimental test cases were compared with numerical simulations using SUTRA (Voss and Provost, 2010). The numerical model consisted of a rectangular domain of the same dimensions as the central viewing chamber in the experimental tank. A mesh refinement study yielded element sizes of $1.27 \mathrm{~mm}$ optimal for accurate determination of WMZs while maintaining reasonable simulation times. The longitudinal and transverse dispersivity values were determined by a trial and error process, but ultimately fell within the range specified by Abarca and Clement (2009) for beads of a similar size. The dispersivity values and element dimensions provided numerical stability in the simulations by meeting the criterion for mesh Peclet number (Voss and Provost, 2010). A freshwater $(C=0)$ hydrostatic boundary condition is forced on the left side boundary and a hydrostatic saltwater ( $C=100 \%)$ boundary condition applied to the right side, as shown in Fig 2 . 


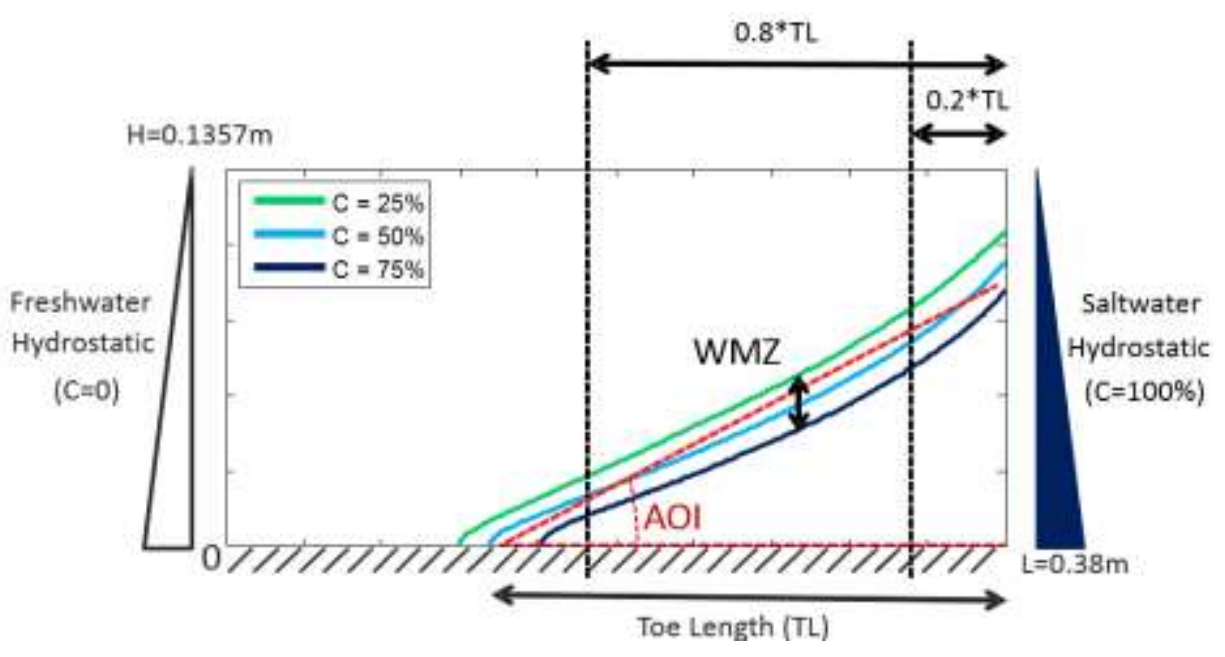

Fig 2 - Reference schematic for analysed intrusion parameters

The same head difference cases described in the previous section were simulated using SUTRA. Results were calculated for a time step of 1 s over a 50 minute period, where all cases reached a steady state condition. An intrinsic flow test on the experimental domain allowed calculation of the permeability of the porous media using Darcy's law. The model input parameters are summarised in Table 2.

Table 2 - SUTRA simulation input summary

\begin{tabular}{lrl}
\hline Input Parameters & Value & Unit \\
\hline Domain size, L x & $0.38 \times 0.1357$ & $\mathrm{~m}$ \\
Element size & $1.27 \mathrm{E}-03$ & $\mathrm{~m}$ \\
Permeability: & & \\
$-780 \mu \mathrm{m}$ & $7.98 \mathrm{E}-10$ & $\mathrm{~m}^{2}$ \\
$-1090 \mu \mathrm{m}$ & $1.83 \mathrm{E}-09$ & $\mathrm{~m}^{2}$ \\
$-1325 \mu \mathrm{m}$ & $2.39 \mathrm{E}-09$ & $\mathrm{~m}^{2}$ \\
Porosity & 0.385 & \\
Molecular diffusivity & $1.00 \mathrm{E}-09$ & $\mathrm{~m}^{2} / \mathrm{s}$ \\
Longitudinal dispersivity & $1 \mathrm{E}-03$ & $\mathrm{~m}$ \\
Transverse dispersivity & $5 \mathrm{E}-05$ & $\mathrm{~m}$ \\
Freshwater density & 1000 & $\mathrm{~kg} / \mathrm{m}^{3}$ \\
Saltwater density & 1025 & $\mathrm{~kg} / \mathrm{m}^{3}$ \\
Dynamic viscosity & 0.001 & $\mathrm{~kg} / \mathrm{m} / \mathrm{s}$ \\
Head difference, dH & $6,4,5$ & $\mathrm{~mm}$ \\
Simulation time & 50 & $\mathrm{mins}$ \\
Time step & 1 & $\mathrm{~s}$ \\
\hline
\end{tabular}




\section{Results and Discussion}

The discussion of results is divided into two main sections, steady state analysis and transient analysis. However, in some cases the steady state intrusion parameters can be related to, or explained by, the hydrodynamics of the transient results. Therefore, there may be discussion crossover between sections. Fig 2 shows how each intrusion parameter was calculated.

A representative case was chosen out of the three physical repeats for each bead class. These cases represent the median intrusions in each bead class; cases that did not produce either high or low intrusion extremes. The representative cases are analysed in detail in the following sections, but results of every case are discussed later in the repeatability section.

\subsection{Steady state analysis}

The $T L$ is the distance that the $50 \%$ saltwater concentration isoline has penetrated the aquifer from the saltwater boundary (Fig 2). The $50 \%$ concentration isolines for every steady state head difference $(d H=6 \mathrm{~mm}, 4 \mathrm{~mm} \& 5 \mathrm{~mm})$ are shown in Fig 3 for the representative $1090 \mu \mathrm{m}$ case. During the image analysis procedure, the domain boundaries were offset from the edges of the viewing window due to the disturbed light distributions observed at these locations.

Fig 3 presents the $50 \%$ isolines relative to the image space, not the physical sandbox dimensions. Numerical simulations utilise the physical sandbox parameters and the isolines are cropped to image space dimensions. Presented also is the analytical solution by Glover (1964).

The initial head difference applied $(d H=6 \mathrm{~mm})$ prompted the saltwater to intrude into the fully fresh aquifer and form a small wedge at steady state ( Fig 3). As expected, a reduction in head difference $(6-4 \mathrm{~mm})$ produces a landward movement of the saltwater wedge and results in an increased $T L$. With a reduced hydraulic gradient the freshwater could no longer maintain the pressure head required to resist the SWI advancing the saltwater wedge into the aquifer. Likewise, an increase in head difference $(4-5 \mathrm{~mm})$ induced a seaward movement of the saltwater wedge, increasing the freshwater pressure head to drive the toe further out of the aquifer. 


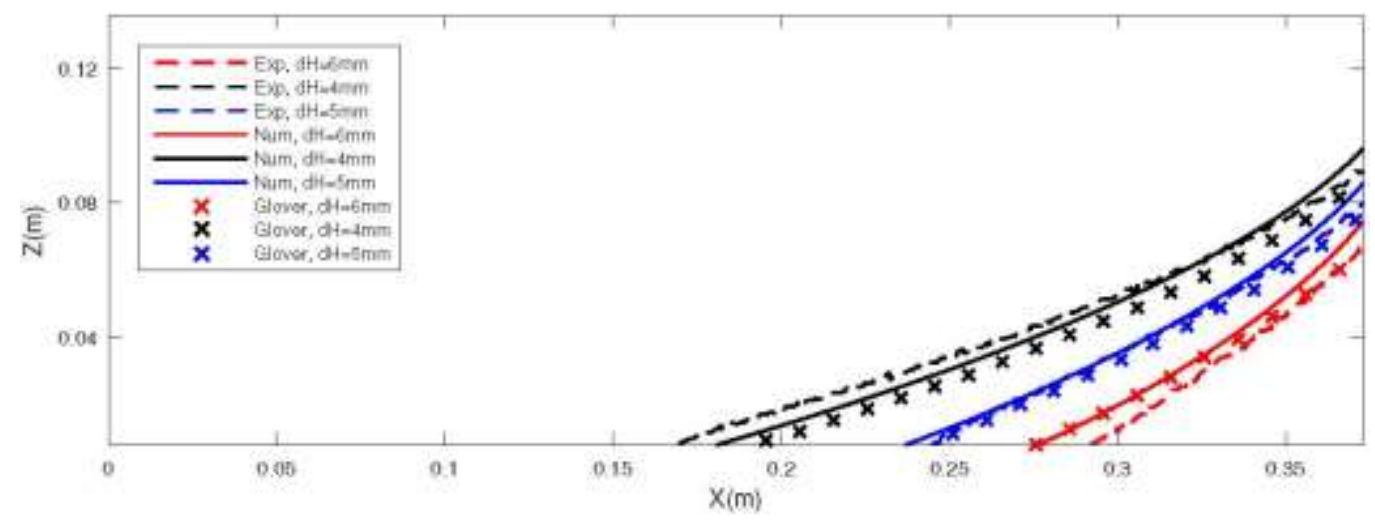

Fig 3 - Experimental, analytical solution by Glover (1964), and numerical steady state $50 \%$ salt concentration isolines for the $1090 \mu \mathrm{m}$ case at head differences, $d H=6 \mathrm{~mm}, 4 \mathrm{~mm} \&$ $5 \mathrm{~mm}$.

The numerical $50 \%$ concentration isolines match well with the experimental results. The numerical results slightly over predict the $T L$ at the $d H=6 \mathrm{~mm}$ case but under predict the $T L$ at $d H=4 \mathrm{~mm}$. At this experimental scale, small errors can occur in the form of water level adjustment, sandbox levelling and uneven flow through mesh boundaries. In order to determine if any past events affect the $T L$, a second head difference case $(d H=5-6 \mathrm{~mm})$ was analysed, with the saltwater wedge receding to a steady state at $d H=6 \mathrm{~mm}$ instead of advancing as before. Comparing the $1090 \mu \mathrm{m}$ bead results, the $T L$ for the $d H=f-6 \mathrm{~mm}$ case was $T L=8.79 \mathrm{~cm}$, while for the $d H=5-6 \mathrm{~mm}$ case $T L=8.82 \mathrm{~cm}$. The difference between the results is around the same size as a single pixel $(0.3 \mathrm{~mm})$ indicating that no hysteresis effects occur in the experiment.

The experimental isolines appear to be more linear in slope, while the numerical is more curved (Fig 3). It can be reasoned that the experimental wedge slopes are more linear in shape due to minor heterogeneities introduced through small variations in bead diameter. Similar changes in saltwater wedge shape have been reported in numerical studies of heterogeneous effects on SWI (Abarca, 2006; Kerrou and Renard, 2010).

The comparison between homogeneous steady state TLs for the 3 bead diameter classes is shown in Fig 4 . The $1090 \mu \mathrm{m} T L$ s are consistently larger than the $780 \mu \mathrm{m}$ and $1325 \mu \mathrm{m}$ results. The results were compared to numerical simulations in order to determine the factors behind this unexpected trend in experimental results. 


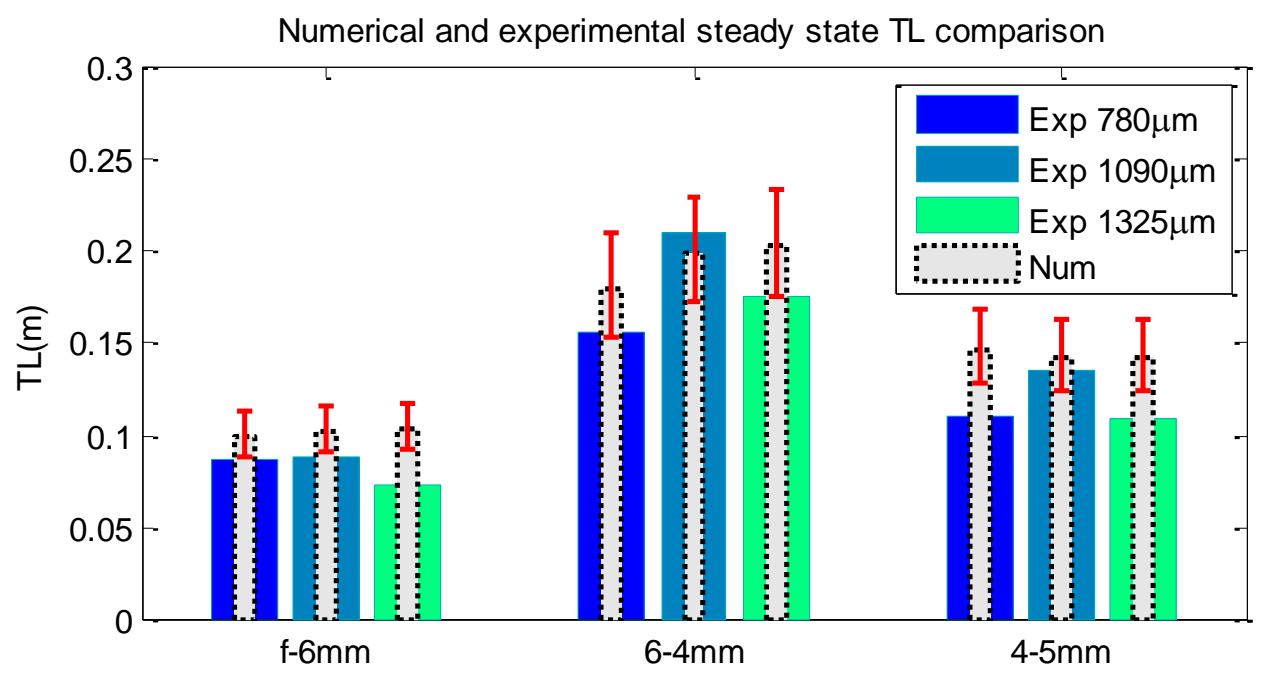

Fig 4 - Experimental and numerical steady state $T L$ results with error bars (red) determined from measurement device error

Investigation into the numerical results revealed very little change in steady state $T L s$ despite changing permeability, as shown in the Fig 4. Previous numerical studies by Abarca (2006) and Dentz et al. (2006) have shown that $T L$ depends on:

1. Permeability of porous media;

2. Longitudinal and transverse dispersivities.

3. Density contrast between saltwater and freshwater;

The numerical model simulates perfect homogeneous conditions and does not take into account bead size deviations around the mean bead diameter or minor heterogeneities introduced during packing. These effects are not clearly identifiable at first in the relatively stable experiments conducted in this work. However, the effect of minor heterogeneities is more clearly observed in the physical experiments. Cremer and Graf (2015) reported distinct fingering patterns in their experimental falling solute plumes for homogeneous media. The creation of these solute fingers is attributed to variations in bead arrangement and size, which perturb the flow by inducing varying pore-scale velocities. Therefore, the permeability values determined from in-situ tests are representative of the average flow through the entire media, but localised flow variations can alter solute movement significantly. This will occur in all experimental studies to some degree and partly provides an explanation for the discrepancy between experimental and numerical results. 
We carried out CAMSIZER analysis for the different beads and results are shown in Fig 5. All the beads show spherical shape with the exception of the $780 \mu \mathrm{m}$ where few beads appear irregular. This may have some contribution to the differences between the numerical and experimental results.

The values for dispersivity were chosen based on a review of similar published laboratory experiments and a trial and error procedure. As discussed earlier, for most laboratory scale experimental studies the size and evolution of the mixing zone is ignored. This study quantifies both transient TLs and WMZs, where the dispersivity values used in the numerical model are crucial in characterising both these saltwater wedge properties. The steady state WMZs for the three bead sizes are presented in Fig 6. At first glance, the $W M Z$ values are small (around $5 \mathrm{~mm}$ ) and generally decrease with increasing bead size. The mixing process at the current laboratory scale is dominated by mechanical dispersion; increasing the WMZ by squeezing saltwater through small pores and dispersing the solute. The larger bead size contains larger pores, therefore reducing dispersion and decreasing the WMZ. This trend is consistent with results from numerical simulations.

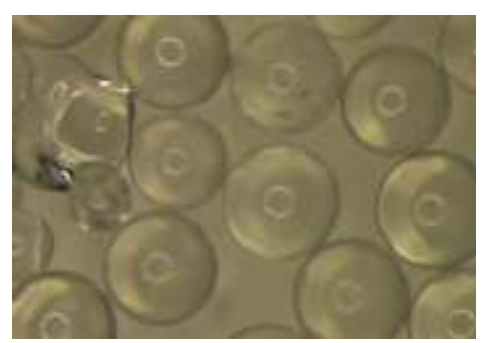

$780 \mu \mathrm{m}$

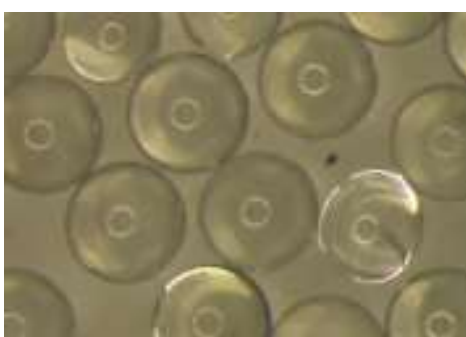

$1090 \mu \mathrm{m}$

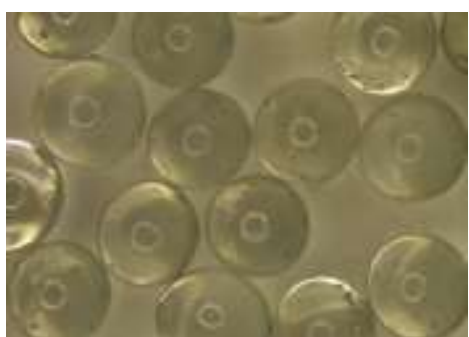

$1325 \mu \mathrm{m}$

Fig 5. Images produced by CAMSIZER analysis for the three beads sizes. 


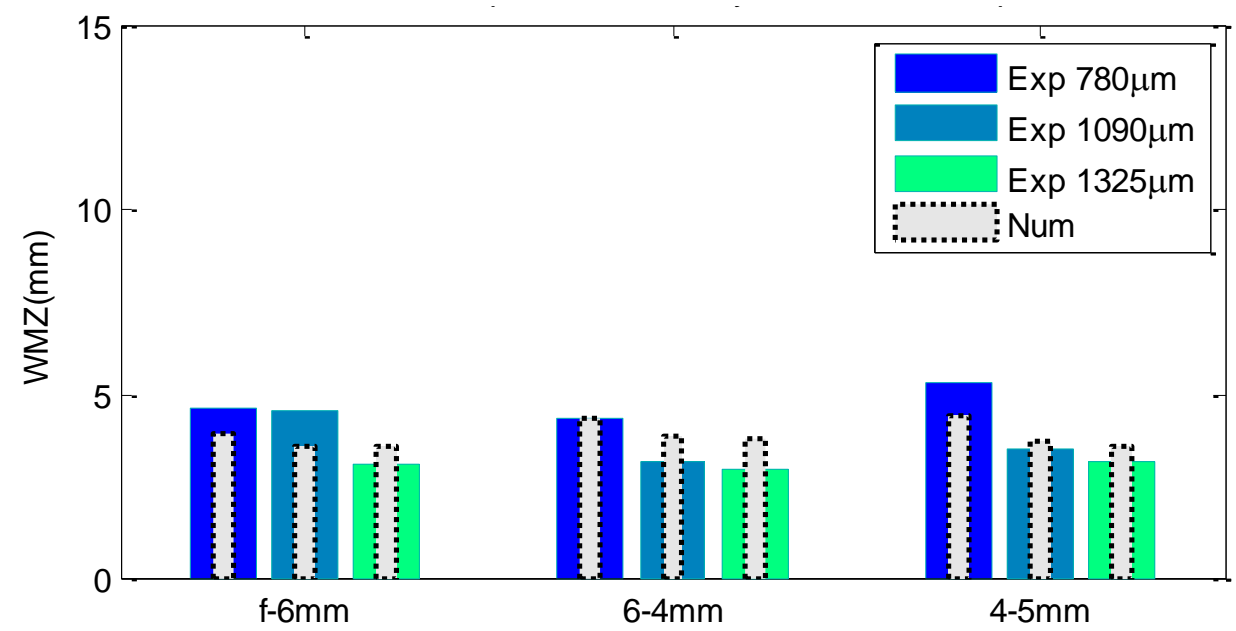

Fig 6 - Steady state WMZ comparison for experimental test cases and numerical simulations.

However, there are discrepancies between the numerical and experimental results. Similarly to the $T L$, the experimental $W M Z$ values vary more than the numerical simulations with changing head differences. This effect can also be attributed to small localised heterogeneities in the experimental domain. It should also be noted that constant dispersivity values were used in the simulations despite changing bead size. This would appear illogical at first because varying pore sizes in different granular media would warrant the use of different dispersivities. A sensitivity analysis was conducted to test the effect of dispersivity on the $T L$ and WMZ. The results are in agreement with Abarca (2006), which showed that increasing both longitudinal and transverse dispersivities resulted in a seaward movement of the $T L$ and an increase in the WMZ. Therefore, changing the dispersivity between different bead classes would sometimes provide a better fit for $T L$, but worsen the fit for WMZ and vica versa.

Variations in solute concentration will also contribute to changes in intrusion $T L$ and the discrepancy between experimental and numerical results. Initially, a new batch of saltwater was mixed for each experiment. Despite careful preparation, small variations in saltwater density may have been generated between mixes. In addition, the lab temperature could also cause slight change in saltwater density. The error involved in the batch mixing can be calculated based on the error in each of the measuring devices used in the process. The calculated error in the measuring devices used to mix the saltwater would result in an overall density difference of $\pm 0.3 \mathrm{~kg} / \mathrm{m}^{3}$. However, in order to take into account other uncontrolled 
factors such as temperature, atmospheric pressure and humidity, a conservative error estimate of $\pm 1 \mathrm{~kg} / \mathrm{m}^{3}$ was modelled for saltwater density. The intrusion $T L$ is also dependant on the hydraulic gradient. The hydraulic gradient imposed across the aquifer was controlled by the water levels in the side chambers. The water levels were measured by ultrasonic sensors accurate to $\pm 0.2 \mathrm{~mm}$. To account for these variations, numerical simulations were conducted based on a minimum and maximum intrusion scenario, as shown in Table 3 . The maximum intrusion scenario is simulated using the error in measurement devices that would provide the smallest head difference and greatest density, while the minimum intrusion scenario has the largest head difference and lowest density.

Table 3-Modified simulation input for maximum and minimum intrusion cases

\begin{tabular}{llrl}
\hline Case & Input Parameters & Value & Unit \\
\hline Maximum intrusion & Head difference, $d H$ & $5.8,3.8,4.8$ & $\mathrm{~mm}$ \\
& Freshwater density & 1000 & $\mathrm{~kg} / \mathrm{m}^{3}$ \\
& Saltwater density & 1026 & $\mathrm{~kg} / \mathrm{m}^{3}$ \\
\hline Minimum intrusion & Head difference, $d H$ & $6.2,4.2,5.2$ & $\mathrm{~mm}$ \\
& Freshwater density & 1000 & $\mathrm{~kg} / \mathrm{m}^{3}$ \\
& Saltwater density & 1024 & $\mathrm{~kg} / \mathrm{m}^{3}$ \\
\hline
\end{tabular}

The $T L s$ from the simulated minimum and maximum intrusions based on measurement error bars are also shown in Fig 4. No significant change in WMZ was observed between minimum and maximum intrusion cases. The experimental results for the $6-4 \mathrm{~mm}$ case fall within the measurement error. For the $\mathrm{f}-6 \mathrm{~mm}$ case, the $780 \mu \mathrm{m}$ and $1090 \mu \mathrm{m}$ TLs lie just outside the measurement error, with less than $3 \mathrm{~mm}$ between the experimental results and the minimum intrusion case.

The experimental $4-5 \mathrm{~mm}$ results show greater deviation from the simulated measurement error bars, however the $1090 \mu \mathrm{m} T L$ does fall within the range. It is important to note that the $1090 \mu \mathrm{m}$ experimental $T L \mathrm{~s}$ match best with numerical simulations. The $1325 \mu \mathrm{m}$ results do not fall within the measurement error and shows the largest deviation from numerical results for the $\mathrm{f}-6 \mathrm{~mm}$ and $4-5 \mathrm{~mm}$ cases. It could be reasoned that this is due to the larger variability in bead diameter and shape. The results from Fig 4 highlights that even small measurement errors can significantly affect $T L$ results at this scale. 


\subsection{Transient Analysis}

This section primarily focuses in identifying trends and features not observable from steady state intrusion parameters. The transient experimental and numerical $\boldsymbol{T} \boldsymbol{L}$ results are shown in Fig 7 for the $1090 \mu \mathrm{m}$ bead class. The transient numerical $\boldsymbol{T} \boldsymbol{L}$ s match well with experimental results for this bead class.

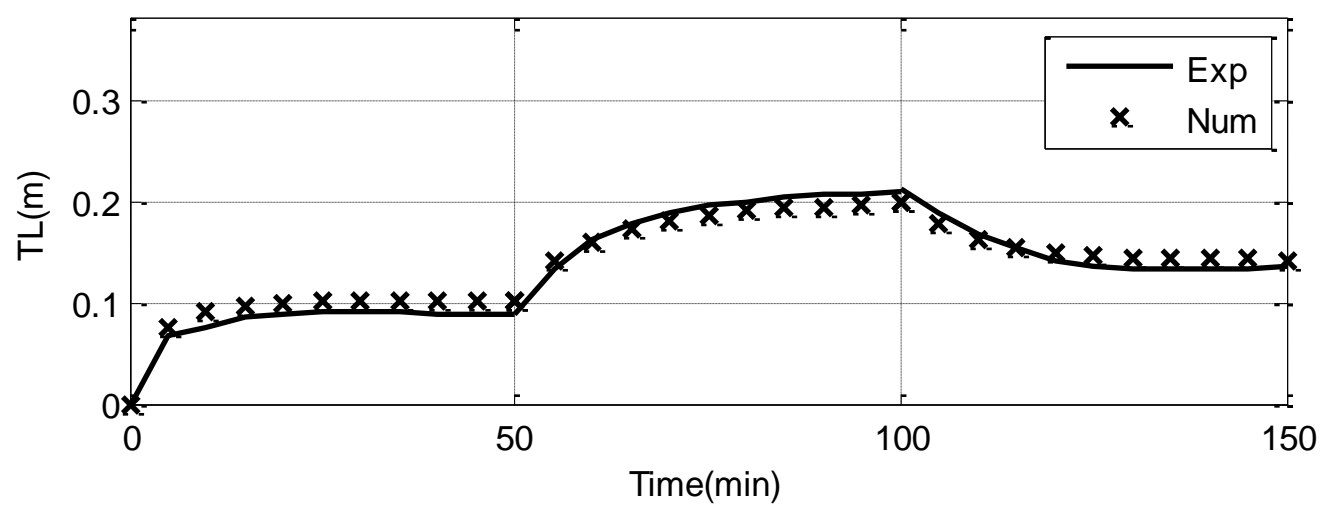

Fig 7 - Transient $T L$ between head difference cases for the $1090 \mu \mathrm{m}$ bead class, where: $t=$ $0-50 \mathrm{mins}, d H=\mathrm{f}-6 \mathrm{~mm} ; t=50-100 \mathrm{mins}, d H=6-4 \mathrm{~mm} ; t=100-150 \mathrm{mins}, d H=4-5 \mathrm{~mm}$

The times to reach steady state compare well, but the rate of wedge intrusion differs slightly. This is evident from the intersection of the experimental line with numerical results in Fig 7 during the $6-4 \mathrm{~mm}$ and $4-5 \mathrm{~mm}$ head difference cases. Previous studies have numerically analysed intrusion timescales based on the toe penetration length (Chang and Clement, 2013; Lu and Werner, 2013b). These studies found that a receding saltwater wedge will reach a steady state condition faster than an advancing wedge. This study investigates timescales from experimental tests to compare with previous numerical theories.

The change in $T L$ with respect to total length travelled during a test case allows for an indication of intrusion rate without the bias of the experimental sensitivity when compared to numerical simulations. Investigating relative intrusion rates within each head difference case also allows for the comparison of advancing and receding intrusion parameters independent of the physical $T L$ values.

The change in $T L$ relative to the distance travelled in a test case $\left(\delta T L_{r}\right)$ is calculated using Equation 2:

$\delta T L(t)=a b s\left[T L\left(t_{n}\right)-T L(t)\right]$ 
$\delta T L_{r}(t)=\delta T L(t) / \delta T L\left(t_{n}\right)$

where $T L(t)$ is the toe length at a given time $\left(t_{1,2, \ldots, n}\right)$ and $n$ is the no. of time steps.

The relative toe length change results are shown in Fig 8 . It should be noted that $T L\left(t_{n}\right)$ is the toe length value at the end of each head difference test and is the same value presented in the steady state results. The time to reach steady state $\left(T_{S}\right)$ is defined as the first instance where the relative change in toe length $\left(\delta T L_{r}\right)$ falls below 0.03 . This condition was chosen arbitrarily; where a $\delta T L_{r}$ of $3 \%$ was a small enough change to be considered as experimental instabilities. Linear interpolation between data points allowed the time to reach steady state to be determined at a higher resolution. Fluctuations in $\delta T L_{r}$ occurring after that time are assumed to be due to minor fluctuations in the water levels at the boundaries.

Fig 8 shows good correlation between relative experimental and numerical intrusion rates. Most notably, the trend in both experimental and numerical results is that the receding case ( $\left.T_{s}=25 \mathrm{mins}\right)$ reaches a steady state condition before the advancing case ( $\left.T_{s}=40 \mathrm{mins}\right)$. The numerical study by Chang and Clement (2013) revealed a difference in the flow field between an advancing and receding saltwater wedge. In an advancing wedge, the bulk movement of the saltwater opposes the movement of the freshwater. In a receding wedge the flow field switches so that the bulk motion of both fluids is tending seaward. This bulk unidirectional flow field allows the saltwater wedge to retreat at a faster rate and reach a steady state condition sooner. Applying this theory to the results of the larger $1325 \mu \mathrm{m}$ bead class, the larger permeability would provide easier movement of the fluids and allow for faster intrusion rates and lower the time to reach steady state. The $\delta T L_{r}$ for the $1325 \mu \mathrm{m}$ case is shown in Fig 9. Similarly to the $1090 \mu \mathrm{m}$ bead class, the experimental results compare well with the numerical simulations. It is evident from Fig 9 hat the results show the expected trends hypothesised from the theory of Chang and Clement (2013). The gradient of the lines at the beginning of the test cases are steeper for the $1325 \mu \mathrm{m}$ bead class, indicating faster intrusion. The $1325 \mu \mathrm{m}$ bead class also reaches a steady state condition faster than the $1090 \mu \mathrm{m}$ results. The time to reach steady state for all bead classes are summarised in Table 4. 


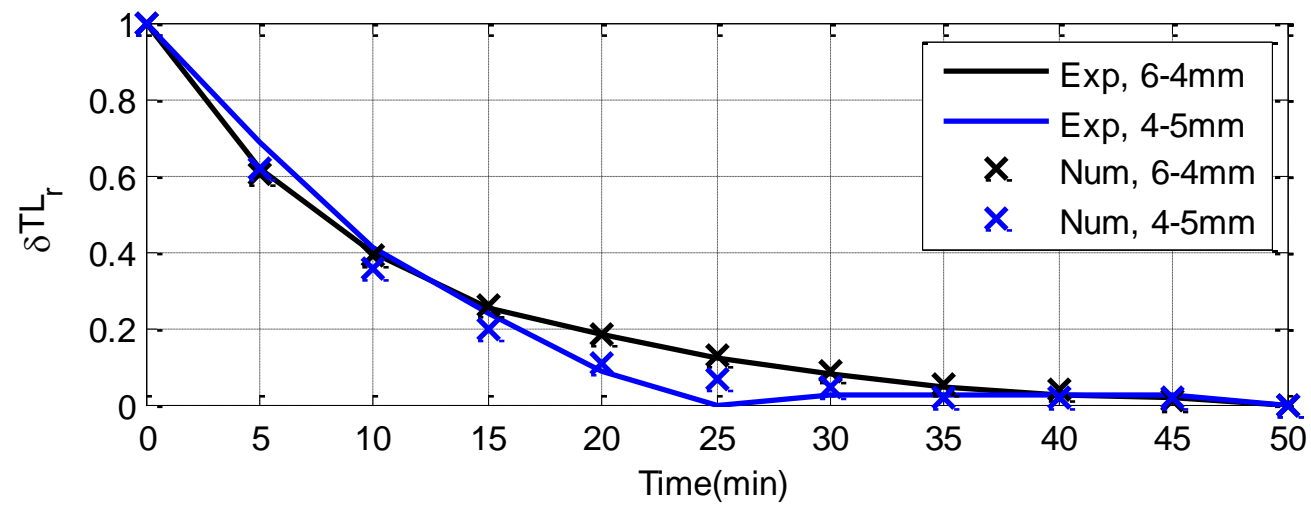

Fig 8 - Change in toe length relative to distance travelled for $1090 \mu \mathrm{m}$ bead class, where $\delta T L_{r}=1$ is the initial intrusion condition and $\delta T L_{r}=0$ is at the final steady state condition.

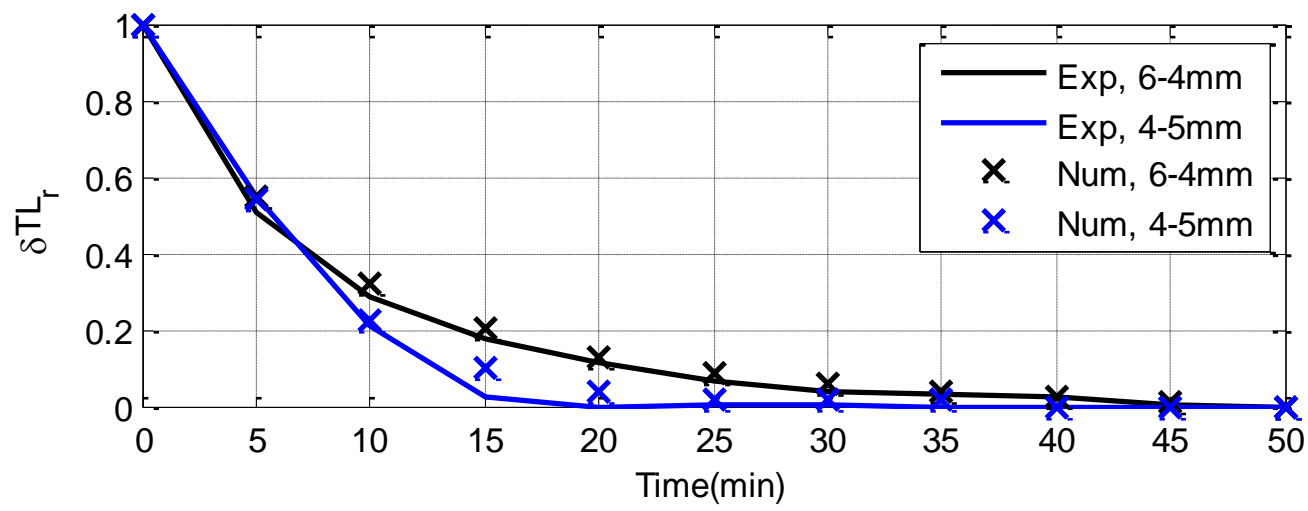

Fig 9- Change in toe length relative to distance travelled during test case for the $1325 \mu \mathrm{m}$ bead class

The $\delta T L_{r}$ results for the $780 \mu \mathrm{m}$ bead class are presented in Fig 10 . The numerical simulations do not compare as well with the experimental results as in the other bead sizes. At first glance, it seems that the numerical results have not reached a steady state condition. However, extending the simulation time past 50 minutes did not result in a significant change in $T L$. Conversely, the experimental results do follow the general trends discussed previously. The lower permeability of the $780 \mu \mathrm{m}$ bead class slows fluid flow, increasing the time to reach steady state and reducing intrusion rate. The flow field switch hypothesised by Chang and Clement (2013) is also evidenced in the results for each bead class. 


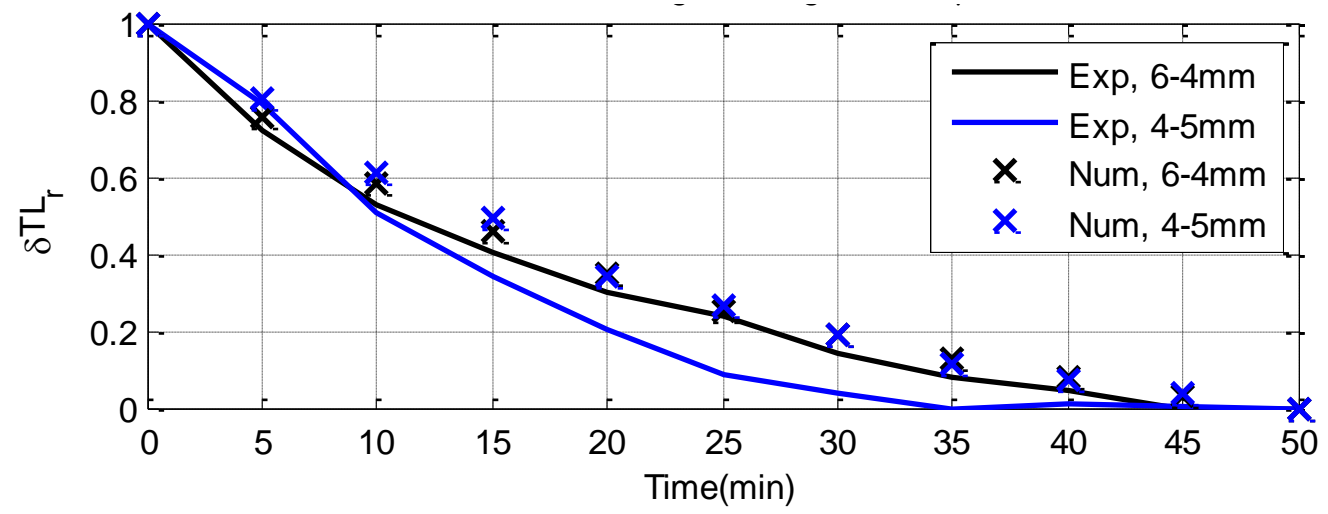

Fig 10 - Change in toe length relative to distance travelled during test case for the $780 \mu \mathrm{m}$ bead class

Table 4-Time to reach steady state for advancing and receding saltwater wedges

\begin{tabular}{ccccccc} 
Time to reach & \multicolumn{2}{c}{$780 \mu \mathrm{m}$} & \multicolumn{2}{c}{$1090 \mu \mathrm{m}$} & \multicolumn{2}{c}{$1325 \mu \mathrm{m}$} \\
steady state (min) & Exp & Num & Exp & Num & Exp & Num \\
$\begin{array}{c}\text { Advancing intrusion } \\
\quad(6-4 \mathrm{~mm})\end{array}$ & 45 & 48 & 40 & 42 & 36 & 37 \\
$\begin{array}{c}\text { Receding intrusion } \\
(4-5 \mathrm{~mm})\end{array}$ & 34 & 46 & 25 & 32 & 16 & 21
\end{tabular}

Looking specifically at the results on initialising a head difference change $(t=0-5 \mathrm{mins})$, the intruding wedge $(6-4 \mathrm{~mm})$ shows consistently steeper gradients and faster intrusion rates than the receding wedge $(4-5 \mathrm{~mm})$. It is only after this period that the receding wedge rate becomes greater than the intruding results, as is observed by the intersecting lines. This can be explained by the switching of the flow fields. Upon increasing the head difference, the flow field requires a short time to adjust to the new pressure distribution and subsequent unidirectional flow regime, therefore decreasing the rate of wedge movement initially. The effect is also more pronounced in the $780 \mu \mathrm{m}$ bead class than in the $1325 \mu \mathrm{m}$ results. This would seem logical in that the lower permeability and slower flow rate of the $780 \mu \mathrm{m}$ bead class would require a longer time to establish the switch in flow field.

The high accuracy calibration methodology adopted in this study allowed quantification of the transient dynamics of the WMZ. Fig 11 shows the results of the transient WMZ for the $1090 \mu \mathrm{m}$ bead class. Unlike the $T L$ results, the disparity between experimental and simulation results is fairly pronounced, particularly after a change in hydraulic gradient. When the 
hydraulic gradient changes the mixing zone expands. For the experimental case, an increase in the WMZ is larger when the saltwater wedge is receding ( $t=100-150 \mathrm{mins}$ ) when compared to the advancing case ( $t=50-100$ mins). In fact, the WMZ almost doubles in size from the previous steady state condition during retreat. The high image conversion and temporal resolutions achieved in this methodology provide information about mixing zone dynamics that highlight its significance and indicate that a sharp interface assumption may not always be suitable for laboratory tests.

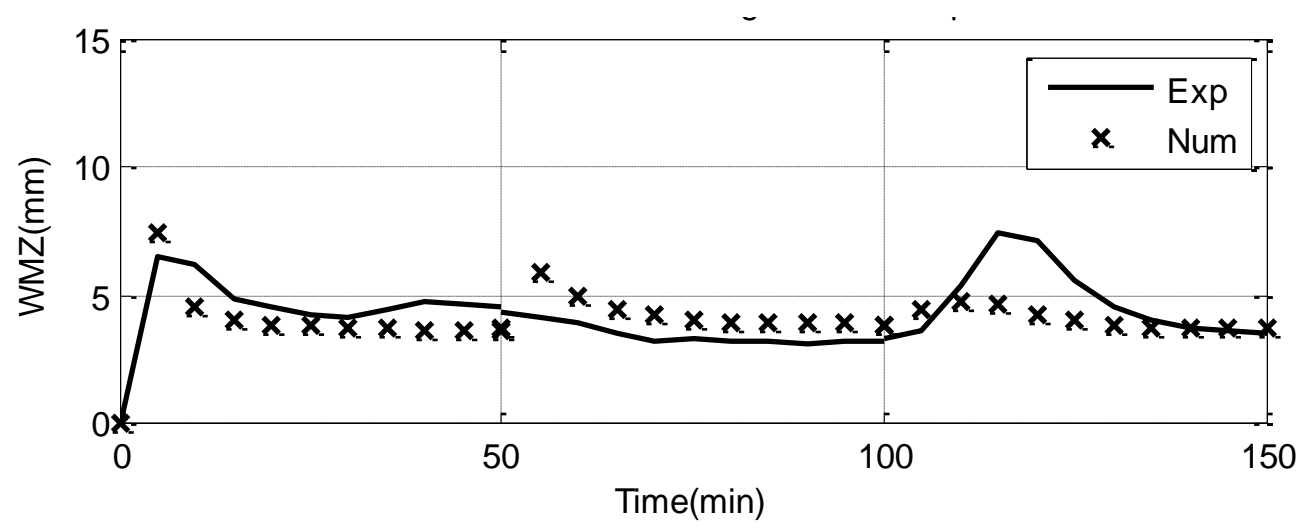

Fig 11 - Transient WMZ between head difference cases for the $1090 \mu \mathrm{m}$ bead class, where: $t$ $=0-50 \mathrm{mins}, d H=\mathrm{f}-6 \mathrm{~mm} ; t=50-100 \mathrm{mins}, d H=6-4 \mathrm{~mm} ; t=100-150 \mathrm{mins}, d H=4-5 \mathrm{~mm}$.

The large increase in experimental WMZ during retreat can be explained by the switch in flow field identified by Chang and Clement (2013). The switch from opposing to unidirectional fluid movements creates a highly disturbed flow field, therefore expanding the saltwater wedge mixing zone. The faster retreat of the saltwater wedge, observed in Fig 8, would also promote higher dispersion along the wedge interface and increase the WMZ. The results for the other bead classes are similar to those shown in Fig 11. However, the size and location of the WMZ peaks are noticeably different between bead classes, as shown in Fig 12 . The $1090 \mu \mathrm{m}$ results show the largest width of mixing zone peak $\left(W M Z_{\text {peak }}\right)$, marginally above the $780 \mu \mathrm{m}$ results. 


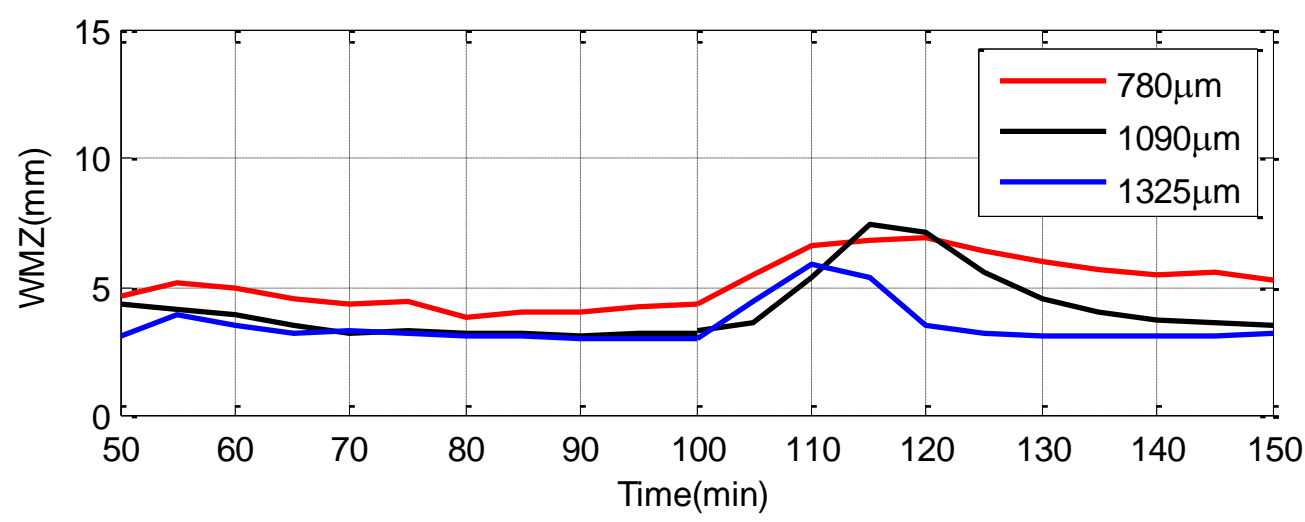

Fig 12 - Experimental transient WMZ comparison for different diameter bead classes during advancing ( $d H=6-4 \mathrm{~mm}, t=50-100 \mathrm{mins})$ and receding ( $d H=4-5 \mathrm{~mm}, t=100-150 \mathrm{mins})$ test cases.

A summary of the $\mathrm{WMZ}_{\text {peak }}$ values for the receding saltwater wedge case is presented in Table. The advancing case generally did not have a distinct peak but rather fluctuated around a mean value. However, for comparison of advancing and receding saltwater wedges a $\mathrm{WMZ}_{\text {peak }}$ value was still determined from Fig 12 . The time to reach the peak value $\left(\mathrm{T}_{\text {peak }}\right)$ gives an indication of the time taken (within each test, 0 -50mins) for the unidirectional flow field to establish, and are also presented in Table . As expected, the increased permeability in the $1325 \mu \mathrm{m}$ bead class facilitated faster establishment of the flow field switch $\left(\mathrm{T}_{\text {peak }}=10 \mathrm{mins}\right)$ when the wedge is prompted to recede. The $\mathrm{T}_{\text {peak }}$ increased as the flow field became more restricted in the smaller bead classes, up to $\mathrm{T}_{\text {peak }}=20 \mathrm{mins}$ for the $780 \mu \mathrm{m}$ bead class. It is important to note that the $T_{\text {peak }}$ value is a multiple of 5 , due to the temporal resolution of 5 minutes used for these homogeneous experiments.

Table 5 - Summary of peak width of mixing zone parameters

\begin{tabular}{ccccccc} 
Width of mixing & \multicolumn{2}{c}{$\mathbf{7 8 0 \mu \mathrm { m }}$} & \multicolumn{2}{c}{$1090 \mu \mathrm{m}$} & \multicolumn{2}{c}{$1325 \mu \mathrm{m}$} \\
$\begin{array}{c}W M Z_{\text {peak }} \\
(\mathrm{mm})\end{array}$ & $\begin{array}{c}T_{\text {peak }} \\
(\mathrm{min})\end{array}$ & $\begin{array}{c}W M Z_{\text {peak }} \\
(\mathrm{mm})\end{array}$ & $\begin{array}{c}T_{\text {peak }} \\
(\mathrm{min})\end{array}$ & $\begin{array}{c}W M Z_{\text {peak }} \\
(\mathrm{mm})\end{array}$ & $\begin{array}{c}T_{\text {peak }} \\
(\mathrm{min})\end{array}$ \\
$\begin{array}{c}\text { Advancing intrusion } \\
(6-4 \mathrm{~mm})\end{array}$ & 5.1 & 5 & 4.4 & 0 & 3.9 & 5 \\
$\begin{array}{c}\text { Receding intrusion } \\
(4-5 \mathrm{~mm})\end{array}$ & 7.0 & 20 & 7.5 & 15 & 5.9 & 10
\end{tabular}

\subsection{Angle of intrusion}

The angle of intrusion $(A O I)$ is a parameter designed to quantify the changes in saltwater isoline gradient as the wedge transitions between head difference cases. This is particularly useful for heterogeneous cases, where the saltwater wedge will have different intrusion 
angles along the interface depending on the media it is flowing through. The $\mathrm{AOI}$ is also useful in defining the mixing zone dynamics in homogeneous tests. The high spatial resolutions of concentration achieved in this study allowed the analysis of individual isoline angles. The $A O I$ values for the $25 \%$ and $75 \%$ saltwater concentration isolines for all bead classes are shown in Fig 13.
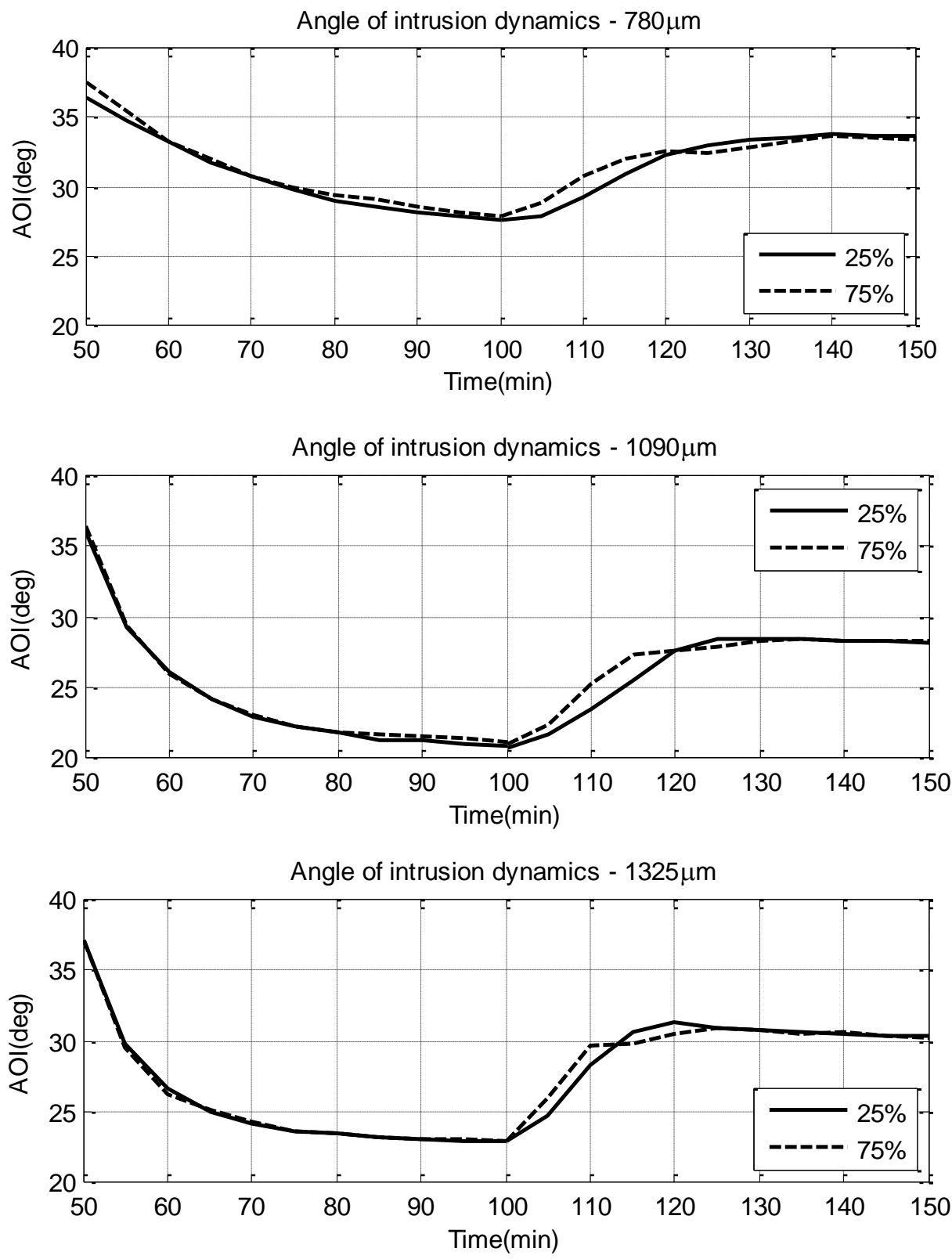

Fig 13 - Experimental angle of intrusions for the $25 \%$ and $75 \%$ concentration isolines during advancing ( $d H=6-4 \mathrm{~mm}, t=50-100 \mathrm{mins})$ and receding ( $d H=4-5 \mathrm{~mm}, t=100-150 \mathrm{mins})$ test cases; $780 \mu \mathrm{m}$ (top), $1090 \mu \mathrm{m}$ (mid) \& $1325 \mu \mathrm{m}$ (bot) 
As the saltwater wedge intrudes further into the aquifer ( $t=50-100 \mathrm{mins}$ ) the angle of intrusion becomes shallower. The difference between the $25 \%$ and $75 \%$ isolines is small for an advancing wedge, indicating that the $W M Z$ does not change significantly. However, as the saltwater wedge recedes the isolines diverge, resulting in an expansion of the mixing zone. When the wedge is prompted to recede ( $t=100 \mathrm{mins}$ ) the $75 \%$ concentration isoline retreats faster than the $25 \%$ isoline. The change in hydraulic gradient increases freshwater flow into the aquifer, flushing out the saltwater at the toe along the interface and out the top of the wedge at the saltwater boundary. This accumulation of diluted saltwater water resembles a pulse as it travels along the interface. The brackish pulse can be observed starting at the toe position for the $1325 \mu \mathrm{m}$ bead class in Fig 14 . It is important to note that the angles of intrusion are determined from linear least square regression of the isoline coordinates. Therefore, the formation of the pulse acts to increase the gradient of the effective linear $75 \%$ isoline, which results in an increased angle of intrusion. By the same effect, the $25 \%$ isoline shows an effective decrease in angle when considered linear. This explains the divergence in intrusion angle of the $25 \%$ and $75 \%$ isoline at $t=100-112$ mins.

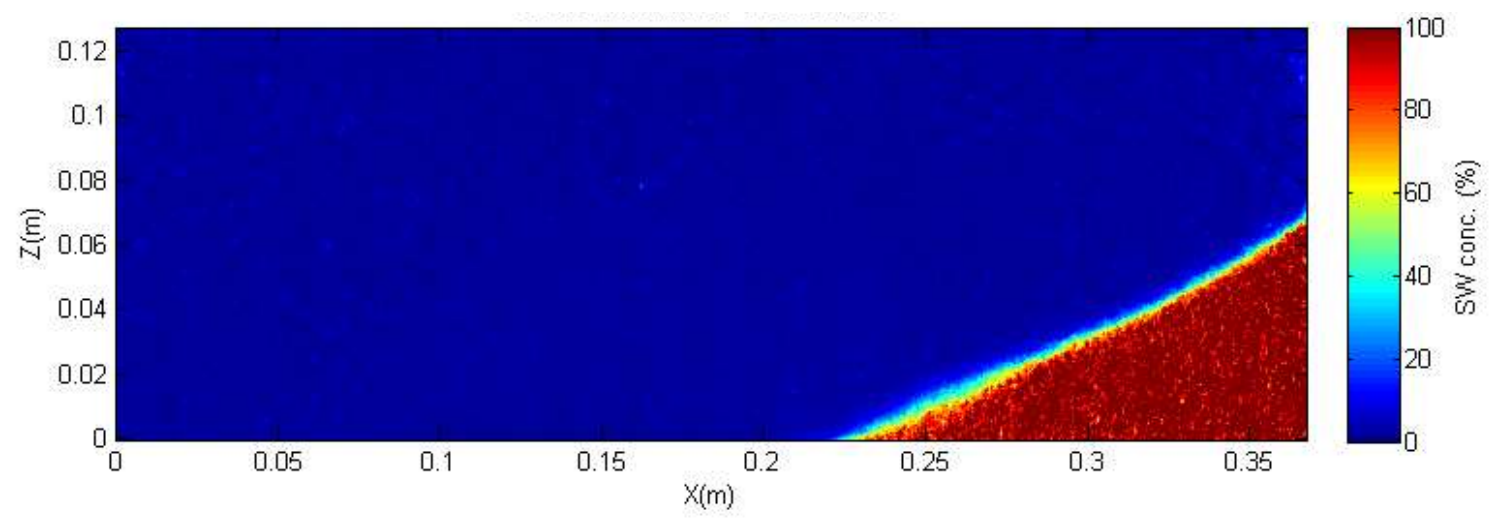

Fig 14 - Concentration colour map at $t=110 \mathrm{mins}$ for the $1325 \mu \mathrm{m}$ bead class, showing the brackish pulse formation at the saltwater wedge toe position.

As the saltwater wedge continues to recede the brackish pulse travels up and along the saltwater-freshwater interface, shown in Fig 15 at $t=115 \mathrm{mins}$ for the $1325 \mu \mathrm{m}$ bead class. It is clear from Fig 15 that the WMZ at the toe position has shrunk, while the brackish pulse caused mixing zone expansion on the middle and upper parts of the saltwater wedge. The 
brackish pulse becomes elongated as it ascends the interface. This can be explained by the higher velocity freshwater pulling the brackish water upward, while the slower velocities in the saltwater wedge restrict that movement. This effect is evident from Fig 13 where the $75 \%$ isoline angle of intrusion stalls and is intersected by the $25 \%$ isoline.

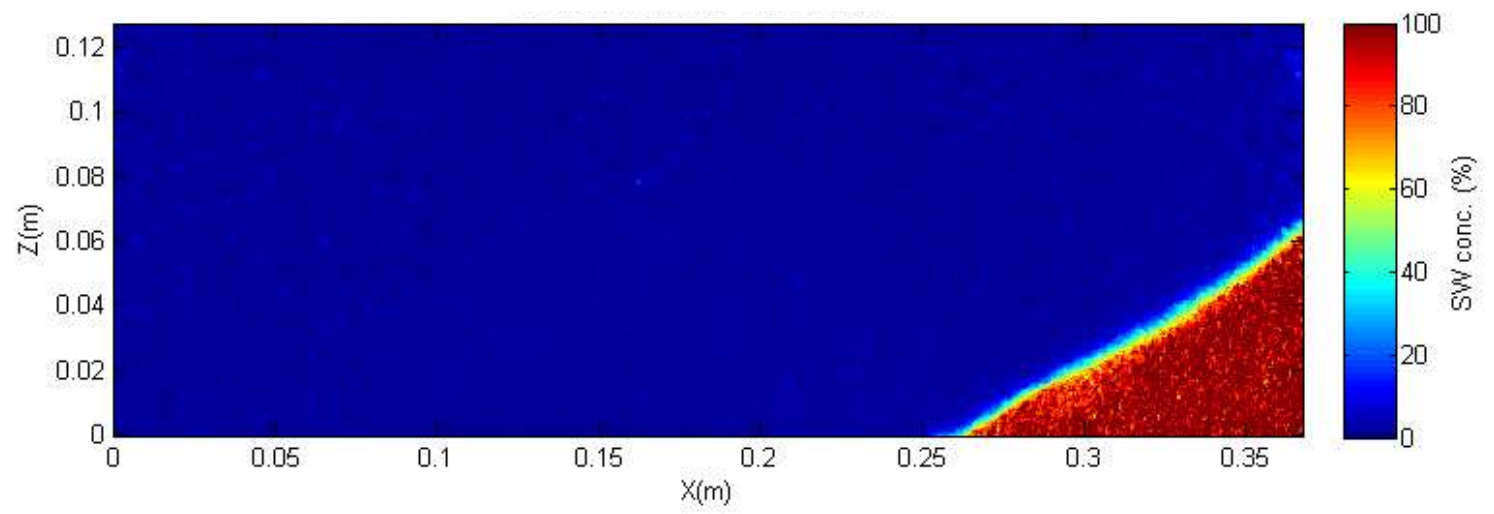

Fig 15 - Concentration colour map at $t=115$ mins for the $1325 \mu \mathrm{m}$ bead class, showing the brackish pulse moving up and along the saltwater-freshwater interface.

At $t=112-123$ mins the $25 \%$ isoline results show a larger gradient than the $75 \%$ isoline. The brackish pulse has the reverse effect on the angle of intrusion values when it is located at the saltwater boundary than at the toe position. The angle of intrusion was also used to calculate a more representative WMZ. By rotating the concentration images by the angle of intrusion, the vertical distances between the $25 \%$ and $75 \%$ isolines are perpendicular to the interface slope. The average of these distances provided WMZs independent of the angle of intrusion. For these homogeneous tests, the trends of the perpendicular width of mixing zone are equivalent to those discussed earlier in this paper and are therefore not presented.

\subsection{Repeatability}

The repeatability of each homogeneous case was assessed by repacking the aquifer with the same bead size and running the same head cases. These physical repeats give an indication of the effect of minor heterogeneities introduced during the packing process. Fig 16 shows the $T L$ and WMZ coefficients of variation for the 4 repeats of the $1090 \mu \mathrm{m}$ bead class. Variations in manual adjustment of the overflows while setting up a new head difference test is also taken into account in the transient results in Fig 16. Nevertheless, for the $1090 \mu \mathrm{m}$ bead class the $T L$ repeatability peaks at $14 \%$ while the WMZ peaks at $20 \%$. The $T L$ repeatability 
across all bead classes is good, with an average coefficient of variation of $12 \%$ and maximum peak of $21 \%$. The WMZ repeatability is generally worse, which is to be expected given its small size. The average WMZ coefficient of variation is $18 \%$ with a maximum peak of $58 \%$.
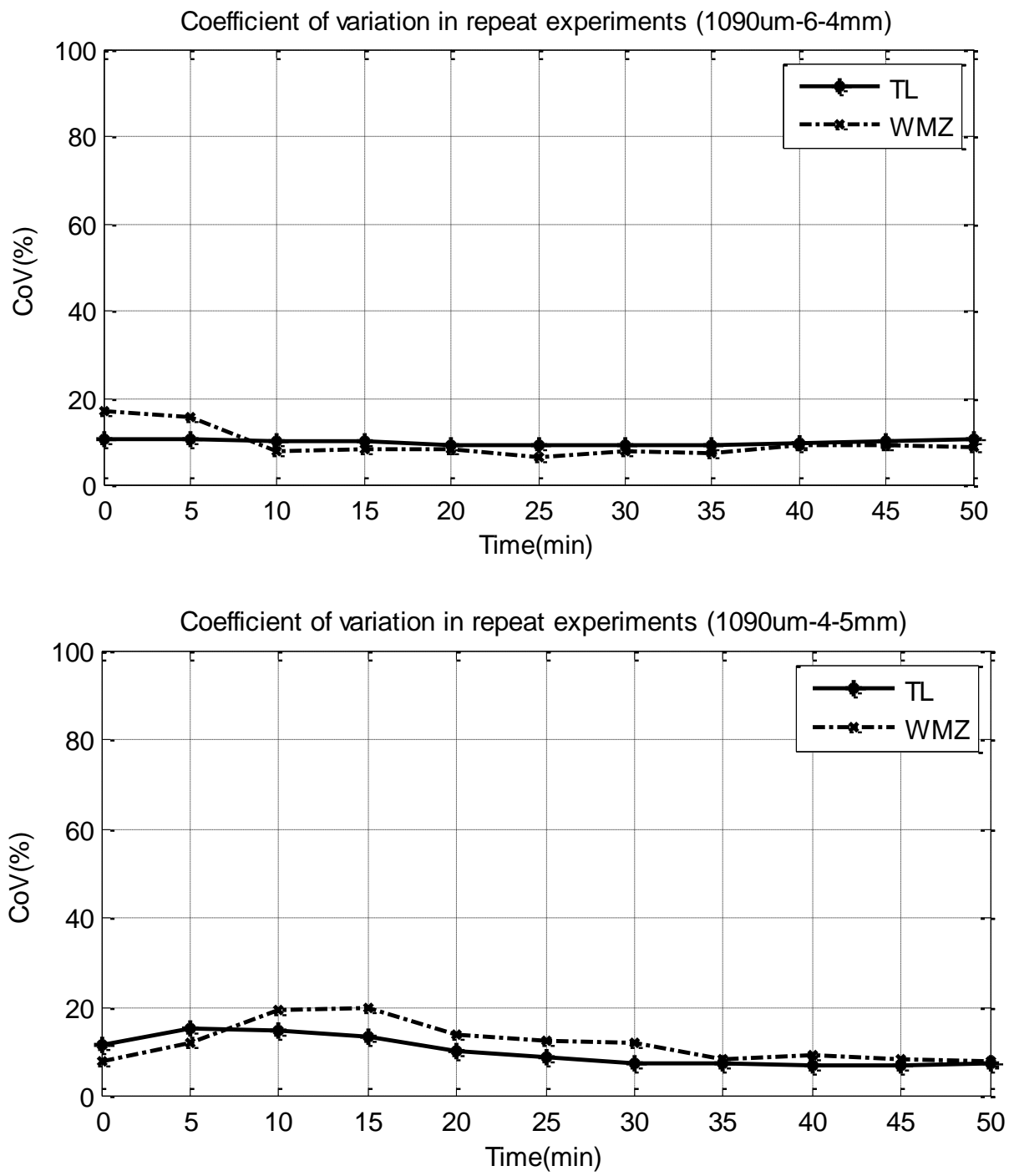

Fig 16 - Transient TL and WMZ coefficients of variation for the 4 physical repeats of the $1090 \mu \mathrm{m}$ bead class during advancing (top) and receding (bot) test cases

It is clear that minor heterogeneities generated during aquifer packing can strongly affect the WMZ. However, several other factors can also be attributed to the large variations between tests. If the camera image is even slightly out of focus it can have a significant effect on quantifying such small mixing zones. As discussed previously, variations in head level adjustment will alter the flow field in the aquifer. Occasionally repeated corrections to the water levels are required in order to achieve the desired head. These fluctuations in pressure 
distribution propagate over time, expanding the WMZ artificially. Considering repeatability is rarely discussed in the literature there is no real study to compare the results to. However, with average coefficients of variation of $<18 \%$ it can be argued that the experimental procedure can quantify intrusion parameters with reasonable accuracy.

\section{Summary and Conclusions}

An experimental study of the hydrodynamics of SWI in synthetic homogeneous aquifers was presented in detail. The high spatial and temporal resolutions achieved by the methodology adopted here allowed for the analysis of intrusion parameters that were not investigated before at experimental scale. This methodology is based automated image analysis technique to compute SWI parameters, which minimises human input, promote autonomy, and provide high resolution image to concentration conversion. The study focused on the comparison of experimental results to numerical simulations for validation, and also the effect of different grain diameters on SWI parameters. An investigation into the errors associated with carrying out the physical experiment was undertaken, culminating in an assessment of the repeatability in terms of $T L$ and WMZ. The main findings of the study are as follows:

1. Analysis of the steady state results discovered that the $1090 \mu \mathrm{m}$ bead class intruded further than both the $780 \mu \mathrm{m}$ and $1325 \mu \mathrm{m}$. Comparison with numerical simulations revealed discrepancies in $T L$ and WMZ. These discrepancies were attributed to several factors, most notably: permeability, dispersivity and density contrast. This prompted an in depth study of the errors associated with the experiment;

2. Identification and quantification of sources of error was based on equipment accuracies and assumptions. A maximum and minimum intrusion case was simulated based on the measuring equipment error to ascertain the significance of the error on intrusion parameters. It was found that generally the experimental results fell within the minimum and maximum intrusion boundaries, but other unknown variables were identified. The effect of unquantified errors (heterogeneity of permeability and dispersivity) were also reviewed and tested by numerical sensitivity analysis and repeats of the physical experiment; 
3. Investigation of the transient results showed good correlation between experimental and numerical intrusion rates. The intrusion rates increased with increasing grain size due to the faster flow field obtained in larger permeability media.

4. The experimental intrusion rates revealed that the saltwater wedge reached a steady state condition sooner while receding than advancing. This was in agreement with an existing theory of flow switching from an opposing flow field to a unidirectional flow field, which was developed in the literature using numerical simulations. Furthermore, the hydrodynamics of the experimental mixing zone exhibited similar traits that could be explained by the theory. A greater increase in the WMZ was observed in the receding saltwater wedge, indicating increased fluid velocities and dispersion.

5. The angle of intrusion analysis revealed the formation of a volume of diluted saltwater at the toe position when a saltwater wedge is prompted to recede. The brackish zone travels up and along the saltwater-freshwater interface, resembling a pulse ('brackish pulse'), and exits out the saltwater boundary. The brackish pulse becomes elongated as it progresses along the interface, which is representative of the velocity differential occurring between the freshwater and saltwater.

6. Physical repeats of the same experiments showed variability in the $T L$ and the WMZ with an average coefficient of variation less than 0.18 .

\section{Acknowledgement}

The authors would like to thank the Department of Employment and Learning (DEL) in Northern Ireland and Queen's University Belfast for funding this project through PhD scholarship to the first author.

\section{References}

Abarca Cameo, E., 2006. Seawater intrusion in complex geological environments. PhD thesis, Department of Geotechnical Engineering and Geo-Sciences (ETCG) Technical University of Catalonia, UPC.

Abarca, E., Clement, T.P., 2009. A novel approach for characterizing the mixing zone of a saltwater wedge. Geophys. Res. Lett. 36 (6), L06402. 
Chang, S.W., Clement, T.P., 2013. Laboratory and numerical investigation of transport processes occurring above and within a saltwater wedge. J. Contam. Hydrol. 147, 14-24.

Chang, S.W., Clement, T.P., 2012. Experimental and numerical investigation of saltwater intrusion dynamics in flux-controlled groundwater systems. Water Resour. Res. 48, W09527..

Cremer, C.J., Graf, T., 2015. Generation of dense plume fingers in saturated-unsaturated homogeneous porous media. J.Contam.Hydrol. 173, 69-82.

Dentz, M., Tartakovsky, D., Abarca, E., Guadagnini, A., Sanchez-Vila, X., Carrera, J., 2006. Variable-density flow in porous media. J.Fluid Mech. 561, 209-235.

Dose, E.J., Stoeckl, L., Houben, G.J., Vacher, H., Vassolo, S., Dietrich, J., et al., 2014. Experiments and modeling of freshwater lenses in layered aquifers: steady state interface geometry. J. Hydrol. 509, 621-630.

Glover, R. E, 1964, The pattern of freshwater flowing in a coastal aquifer, in seawater in coastal aquifers. US Geological Survey Water Supply Paper 1613-C, 32-35

Goswami, R.R., Clement, T.P., 2007. Laboratory-scale investigation of saltwater intrusion dynamics. Water Resour.Res. 43, W04418.

Jakovovic, D., Post, V.E., Werner, A.D., Männicke, O., Hutson, J.L., Simmons, C.T., 2012. Tracer adsorption in sand-tank experiments of saltwater up-coning. J. Hydrol. 414, 476-481.

Kerrou, J., Renard, P., 2010. A numerical analysis of dimensionality and heterogeneity effects on advective dispersive seawater intrusion processes. Hydrogeol.J. 18, 55-72.

Lu, C., Chen, Y., Zhang, C., Luo, J., 2013. Steady-state freshwater-seawater mixing zone in stratified coastal aquifers. J. Hydrol. 505, 24-34.

Lu, C., Werner, A.D., 2013. Timescales of seawater intrusion and retreat. Adv.Water Resour. 59, 39-51.

Luyun, R., Momii, K., Nakagawa, K., 2011. Effects of recharge wells and flow barriers on seawater intrusion. Groundwater. 49, 239-249.

Morgan, L.K., Stoeckl, L., Werner, A.D., Post, V.E., 2013. An assessment of seawater intrusion overshoot using physical and numerical modeling. Water Resour.Res. 49, 65226526.

Robinson, G., Hamill, G., Ahmed, A.A., 2015. Automated image analysis for experimental investigations of salt water intrusion in coastal aquifers. J. Hydrol. 530, 350-360. 
Shi, L., Cui, L., Park, N., Huyakorn, P.S., 2011. Applicability of a sharp-interface model for estimating steady-state salinity at pumping wells - validation against sand tank experiments. J.Contam.Hydrol. 124, 35-42.

Spiteri, C., Slomp, C.P., Tuncay, K., Meile, C., 2008. Modeling biogeochemical processes in subterranean estuaries: Effect of flow dynamics and redox conditions on submarine groundwater discharge of nutrients. Water Resour.Res. 44.

Stoeckl, L., Houben, G., 2012. Flow dynamics and age stratification of freshwater lenses: Experiments and modeling. J. Hydrol.. 458, 9-15.

Voss, C., Provost, A. SUTRA-a model for saturated-unsaturated, variable-density groundwater flow with solute or energy transport. 2010. US Geological Survey Water-Resources Investigations report., 02-4231.

Werner, A.D., Bakker, M., Post, V.E., Vandenbohede, A., Lu, C., Ataie-Ashtiani, B., et al., 2013. Seawater intrusion processes, investigation and management: recent advances and future challenges. Adv.Water Resour. 51, 3-26.

Werner, A.D., Jakovovic, D., Simmons, C.T., 2009. Experimental observations of saltwater up-coning. J. Hydrol. 373, 230-241.

Zhang, Q., Volker, R.E., Lockington, D.A., 2002. Experimental investigation of contaminant transport in coastal groundwater. Adv.Environ.Res. 6, 229-237. 